\title{
SSinteza
}

Impact of Internet on Business Activities in Serbia and Worldwide

Uticaj Interneta na poslovanje u Srbiji i svetu

DOI: 10.15308/SINTEZA-2014-980-983

\section{KONTROLA LETEĆE (QUAD) PLATFORME SA MOBILNIM UREĐAJIMA}

\author{
Željko Stankovići ${ }^{1}$, Dragan Cvetković ${ }^{2}$, Mirza Ramičić1, Zoran Ilić ${ }^{1}$ \\ ${ }^{1}$ Fakultet za informatiku i računarstvo, Univerzitet Apeiron, BIH, Republika Srpska \\ ${ }^{2}$ Fakultet za informatiku i računarstvo, Univerzitet Singidunum, Beograd Srbija
}

\begin{abstract}
:
Ovaj rad predstavlja pregled novog koncepta za moguću primenu pametnih mobilnih uređaja (smart telefona, tableta) na polju kontrole embedid uređaja. Praktičan rad koji je urađen (kontrola leteće quad platforme) predstavljen je u dve ravni . Prva ravan je kontrola leteće platforme sa mobilnih uređaja u definisanom okruženju (postoje komunikacioni uslovi). Drugi plan je percepcija okruženja, održavanje komunikacije kao i bezbednosni sistem same platforme. Rad predstavlja odličnu osnovu za eksperimentalnu nastavu programiranja i robotike. Predložena rešenja zasnovana su na istraživanjima koja su realizovana na pravim modelima.
\end{abstract}

\section{Key words:}

leteća platforma, bespilotna letilica.

\section{UVOD}

Nova istraživanja na polju robotizovanih letećih platformi (bespilotnih letilica, skr. BL) omogućila su proširenje primene bespilotnih letilica. Pored primarne upotrebe u vojne svrhe lepeza korišćenja BL sada se proširuje i na industrijsku upotrebu, kao što je nadgledanje, praćenje ili snimanje. Sa letećim platformama mnogo je jeftinije obaviti snimanja terena iz vazduha namenskim kamerama (geografska i geološka istraživanja).

Takođe, sa ubrzanim razvojem elektronskih komponenti i bežičnih komunikacionih tehnologija, civilne bespilotne letilice postaju mnogo praktičnije instalacijom pristupačnih senzorskih modula i kamera u svrhu prikupljanja podatka u realnom vremenu.

Sa druge strane, vidimo porast velikog broja mobilnih uređaja koji predstavljaju potpune softverske platforme sposobne da nude širok spektar aplikacija zajedno sa brzim pristupom globalnoj mreži. To ih čini idealnim platformama za kontrolu robotizovanih letećih platformi.

Postoje tri fundamentalana sloja operacija robotskih platformi: teleoperativna, reaktivna i planska.
Kontekst teleoperacije podrazumeva da je distanca između robotske platforme i operatora isuviše velika da bi operator mogao da opaža ponašanje te plaforme. U našem slučaju ta funkcija je obezbeđena internet protokolom koji predstavlja siguran i pouzdan metod komunikacije između operatera i platforme koji nije ograničen njihovom međusobnom udaljenosti. Koristeći interfejs za operatera koji je realizovan na mobilnoj platformi ovaj rad pokušava da eliminiše kompleksne i velike sisteme za kontrolu kako bi omogućio pristup teleoperateru bez obzira na njegovu lokaciju.

\section{KONCEPT LETEĆE PLATFORME}

Osnovna svrha teleopracije u našem sistemu je polu-automatska kontrola, često nazivana supervizorska u kojoj leteća platforma prima instrukcije od strane operatera koje kasnije izvršava autonomno (npr. korekcija putanje). Ove akcije u našem slučaju predstavljaju, auto poletanje/sletanje i automatsko održavanje visine letilice. Leteća platforma koja se koristi ima četiri pogonska motora (quad), slika 2.1.. 


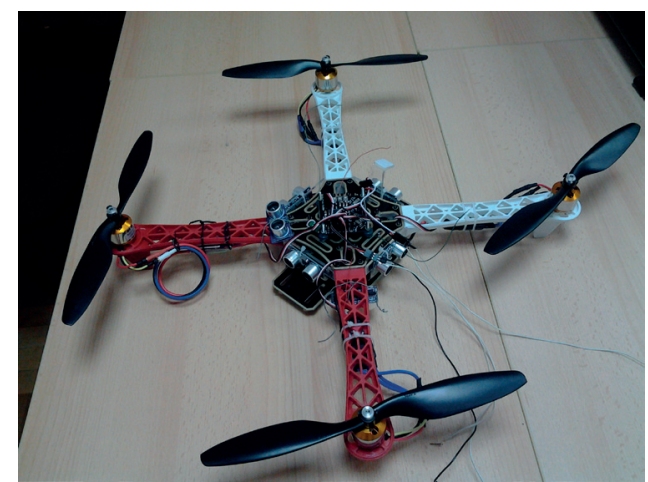

Slika 2.1 Eksperimentalni model quad leteće platforme

\section{PRIMENA HARDVERSKIH MODULA LETEĆE PLATFORME}

Sistem prikazan u ovom radu koristi embedded sistem [1], za kontrolu koji ujedno vrši i funkciju servera. Server se u ovom slučaju sastoji od Arduino Due embedded sistema sa WiFi ili GPRS modulom. Klijentska strana odnosno strana teleoperatera je realizovana pomoću Android mobilne platforme. dela:

Arduino [3] programski kod sastoji se od 2 osnovna

- Prvo podešavanje - setup ()

- Programa koji se izvršava stalno - $\operatorname{loop}()$

Setup() predstavlja deo koda kojim se vrši podešavanje Arduino kontrolera (ulaza i izlaza, komunikacije sa računarom ili nekim drugim uređajem i slično).

Loop() je deo koda koji Arduino stalno ponavlja. Naime, ako bismo Arduino pustili da uradi program jednom on bi završio brzo i morali bismo da ga resetujemo da bi radio ponovo. Ovako kontroler može da se ponaša kao pametan uređaj i da stalno osluškuje komande i prati svoju okolinu.

Na slici 3.1 prikazan je dijagram toka na primenjenoj Arduino ploči.

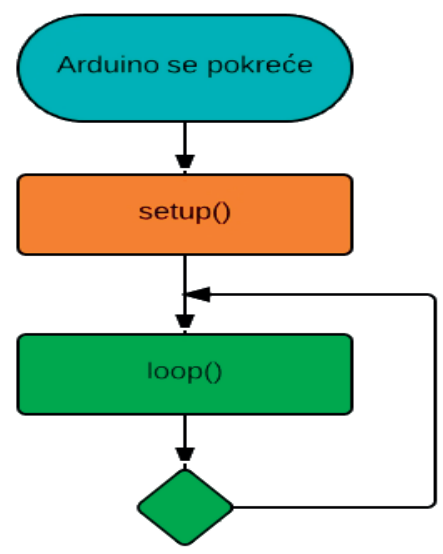

Slika 3.1 Funkcionalni dijagram izvršavanja programa na Arduino ploči

Da bi smo koristili Arduino kao server potrebno je da spojimo WiFi ili GPRS modul i da koristimo WiFi / GPRS bibliteke.

Android mobilna aplikacija izrađena je koristeći Eclipse razvojni softverski paket [2].
Arduino embedded sistem je direktno povezan sa Multirotor kontrolnom pločom (verzija KK2.0). Pomenuti hardver omogućava stabilnost i lakšu kontrolu bespilotne letilice kada je u vazduhu. Na slici 3.2. vidimo da je moguće kontrolisati sve aspekte leta kao i sliku sa kamere instalirane na samoj letelici.

Multirotor kontrolna ploča poseduje ulaze koji su namenjeni kontroli preko radio upravljača (TX/RX). Ulazi se sastoje od pina za uzemljenje, pina za napon napajanja od $5 \mathrm{~V}$ kao i pina za signal.

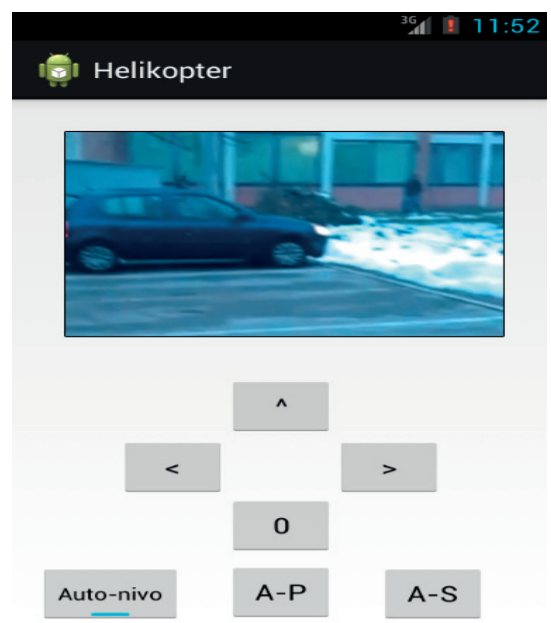

Slika 3.2. Prikaz korisničkog interfejsa mobilne aplikacije

Signali koji dolaze na ulaze kontrolne ploče koriste modulaciju dužine pulsa (eng. Pulse-width modulation) skraćeno PWM, kako bi kontrolisali rad servo motora. $\mathrm{Na}$ slici 3.3. prikazano je povezivanje sa kontrolnom pločom.

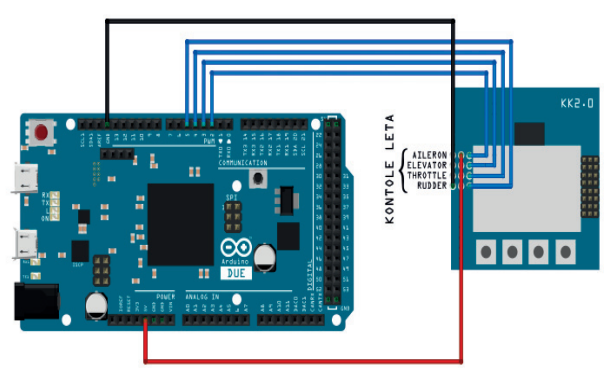

Slika 3.3. Povezivanje Arduino sistema sa kontrolnom pločom leteće platforme

Da bi omogućio autonomno funkcionisanje letilice Arduino embedded sistem preuzima kontrolu nad određenim sekvencama leta.

Funkcije kao što su auto-sletanje, auto-poletanje i izbegavanje objekata u mnogome zavise od senzora. U ovom projektu korišćeni su HC-SR04 ultrasonični senzori. Detekcija predmeta moguća je u rasponu do $0.03 \mathrm{~m}$ do $3 \mathrm{~m}$. U svim testovima leteće platforme reakcija na prepreke bila je dobra. Arduino embedded sistem je programiran da vrši korekcije visine letelice na bazi merenja senzora za visinu. Mikrokontroler konstantno proverava udaljenost letilice od podloge i koriguje brzinu motora kako bi održavao letilicu na konstantnoj visini. Na slici 3.4. ilustrovan je način na koji se koriste senzori HC-SR04. 


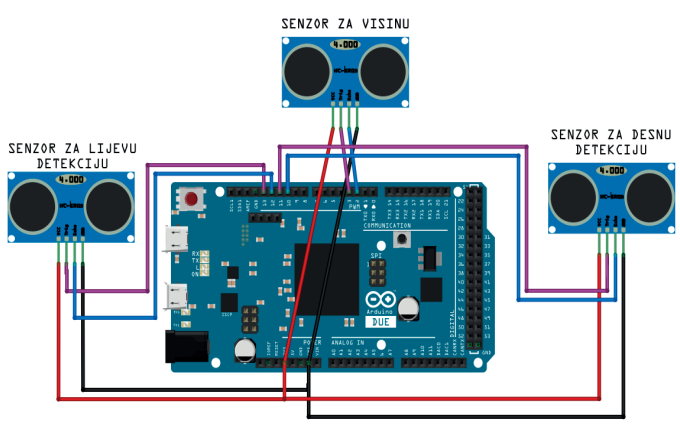

Slika 3.4. Povezivanje Arduino embedded sistema sa senzorima

Funkcionisanje kontrolnog programa može se prikazati i dijagramom toka na slici 3.5. Korekcija obrtaja motora se radi samo kada je to potrebno kako bi obezbedili željenu visinu.

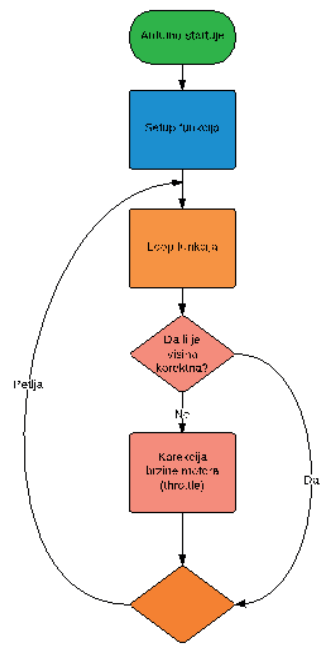

Slika 3.5. Dijagram toka programa za kontrolu visine leteće platforme

Funkcije za sletanje odnosno poletanje realizuju se na sličan način kao i funkcija održavanja visine letilice. Ultrazvučnim senzorom prati se proces poletanja/sletanja od početka do kraja korigujući brzinu motora. Kada senzor detektuje da je letilica već u vazduhu, Arduino diskretno koriguje brzinu motora kako bi poletanje bilo što "tečnije".

Arduino embedded sistem je takođe povezan sa GPS modulom koji platformi omogućava određivanje trenutne lokacije u realnom vremenu. Samo povezivanje kontrolera i GPS modula vidi se na slici 3.6.

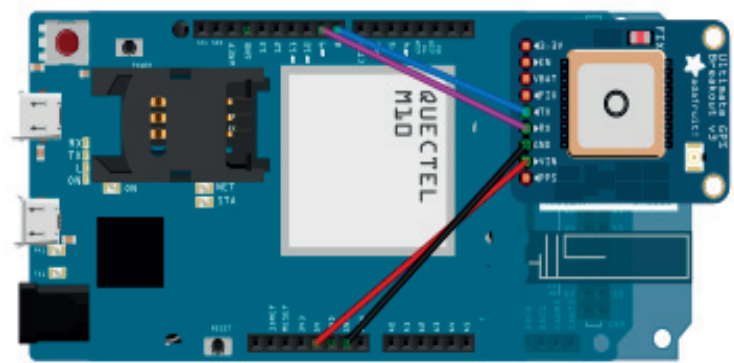

Slika 3.6. Povezivanje GPS modula sa Arduinom i GSM modulom
U trenutku pisanja ovog rada realizovana je funkcija prikazivanja lokacije letilice odnosno njenih GPS koordinata putem mobilne aplikacije kao što je prikazano na slici 3.7.

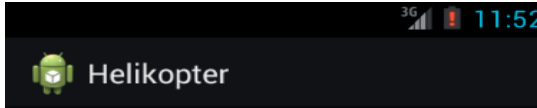

\$GPGGA,154654,4428.2011,N,00440. \$GPGSA, A, $1, \ldots, \ldots, \ldots, \ldots, \ldots, \ldots * 1 \mathrm{E}$ \$GPGSV, 3,1,10,02,50,290,00 \$GPGGA, 154655,4328.1874, N, 00340

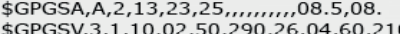
\$GPGSV, $3,1,10,02,50,290,26,04,60,210$ \$GPGSV, $3,2,10,13,58,044,34,16,03,035$ \$GPRMC, 154655,A,4428.1874, N,00440

Time in UTC (HhMmSs): 154653 Status $(\mathrm{A}=\mathrm{OK}, \mathrm{V}=\mathrm{KO})$ : $\mathrm{V}$

Latitude: 4428.2011

Longitude: 00440.5161

Direction (E/W): W

Speed in knots: 000.5

Direction in degrees: 342.8

Date in UTC (DdMmAa): 050407

Magnetic variation:

Variation $(E / W)$ :

Mode: A

Slika 3.7. Ispisivanje GPS koordinata letilice na mobilnoj platformi

Jedna od bitnih funkcionalnosti koja je realizovana je postavljanje odredišnih tačaka na osnovu GPS koordinata koje bi bespilotna letilica trebala da izvršava. Izvršavanje komandi je sekvencijalno po zadanom redu čekanja. Mobilna aplikacija omogućava postavljanje novih odredišnih tačaka upisivanjem GPS koordinata. Koordinate se šalju Arduino sistemu koji nakon toga $\mathrm{u}$ automatskom modu upravlja robotizovanom letećom platformom do odredišne tačke. Na slici 3.8. vidi se rudimentalan interfejs na mobilnom uređaju.

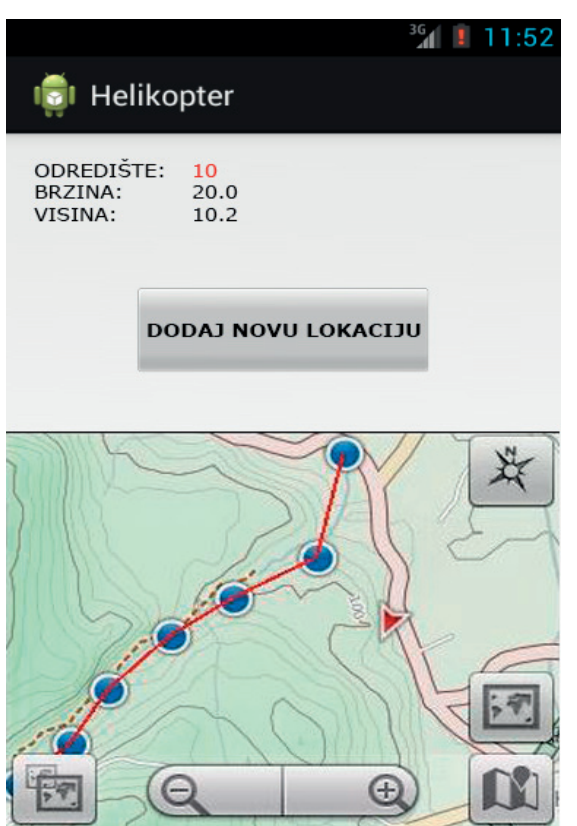

Slika 3.8. Sistem navođenja na osnovu odredišnih tačaka 


\section{ZAKLJUČAK}

Inteligentni robotizovani leteći sistemi sa dinamičkim interfejsom za pametne telefone i tablet uređaje sigurno će biti dobra eksperimentalna platforma. Sa dodatnim senzorima, GPS modulom i bežičnom kamerom bespilotna letilica može se koristiti za širok spektar nastavnih modula u oblasti robotike, programiranja, mehatronike i elektronike.

Predložena leteća platforma predstavlja osnovu za dalji razvoj jednostavnih bespilotnih letilica, a predložena rešenja su prvi korak i idealno polazište za savremenu eksperimentalnu nastavu.

\section{REFERENCE}

[1] Principles of Embedded Computing System Design Marilyn Wolf, Morgan Kaufmann; (2008)

[2] Android Programming Unleashed, B.M. Harwani, Sams Publishing; (2012)

[3] Arduino Robotics, John-David Warren, Apress; (2011)

\section{CONTROL OF FLYING (QUAD) PLATFORM WITH MOBILE DEVICES}

\section{Abstract:}

This paper presents an overview of a new concept for the possible application of smart mobile devices (smartphones, tablets) in the field of control embedid devices. Practical work is done (control flying quad platform) was presented at two levels. The first plane is flying control platform from mobile devices in a defined environment (there are communication requirements). The second plan is the perception of the environment, the maintenance of communications and security system of the platform. The paper provides an excellent basis for experimental teaching programming and robotics. The proposed solutions are based on research carried out on real models.

Key words:

flying quad platform, drones. 